\title{
ALTERNATE COEXISTENCE OF NADPH-DIAPHORASE WITH CHOLINE ACETYLTRANSFERASE OR SOMATOSTATIN IN THE RAT NEOSTRIATUM AND BASAL FOREBRAIN
}

\author{
ANDREAS SCHOBER*, KURT BRAUER ${ }^{* *}$ AND HANS LUPPA*** \\ Academy of Sciences, Institute for Neurobiology and Brain Research, Leipziger Strasse 44, \\ GDR-3090 Magdeburg*, Karl Marx University Leipzig, Paul Flechsig Institute \\ of Brain Research, Dept. of Neuroanatomy, Emilien Strasse 14, GDR-7010 \\ Leipzig**, and Section of Biosciences, Talstrasse 33, \\ GDR-7010 Leipzig***
}

Received for publication July 25, 1989 and in revised form October 12, 1989

\begin{abstract}
The coexistence of reduced nicotinamide adenine dinucleotide phosphate diaphorase (NADPH-d) with somatostatin (SOM) and choline acetyltransferase (ChAT) was compared between the rat neostriatum (ST) and basal forebrain complex (BF). NADPH-d coexists with SOM in ST, but not in the ventral pallidum (VP), in the substantia innominata-nucleus basalis complex (SI-NB) and in the magnocellular preoptic nucleus (NPM) of the BF. In the medial septal nucleus as well as in the vertical and the horizontal limbs of the diagonal band (MS-vDB, hDB) representing the rostral BF and in the SI-NB, a high number of ChATpositive cells also contain NADPH-d. The NPM shows a smaller number of double-stained cholinergic neurons. The functional significance of the NADPH-d coexistence in BF cholinergic cells is still unknown.
\end{abstract}

Whereas the NADPH-d is known to coexist with SOM in a population of interneurons distributed throughout the rat ST, the cholinergic interneurons of this region constantly show negative reactions after treatment according to the NADPH-d histochemistry $(15,17)$. In the $\mathrm{BF}$, where the cholinergic cells represent the predominant neuronal component $(2,8)$ the occurrence of SOM containing cells is restricted to some parts of this unhomogeneous region (1). In the present study we follow the questions: a) Do SOM and ChAT immunoreactive neurons occur with coexisting NADPH-d in the rat BF? b) Are there regional differences in the distribution of double- and single-labelled cells in the BF?

\section{MATERIALS AND METHODS}

Wistar rats were anaesthetized and perfused transcardially with a fixative of $4 \%$ paraformaldehyde in $0.1 \mathrm{M}$ phosphate buffer (PB), $\mathrm{pH}$ 7.4. After removing the brains an immersion fixation of $12 \mathrm{hr}$ followed. The forebrains were dissected out

Address reprint requests to: Andreas Schober, Karl Marx University Leipzig, Section of Biosciences, Talstrasse 33, GDR-7010 Leipzig. 
and placed for $12 \mathrm{hr}$ in $20 \%$ sucrose (in $\mathrm{PB}$ at $4^{\circ} \mathrm{C}$ ). $40 \mu \mathrm{m}$ vibratome slices (Oxford Lab., USA) were prepared and washed in PB (containing $0.2 \%$ Triton X-100) overnight. NADPH-d histochemistry was performed according to Scherer-Singler (10). After this enzymehistochemical procedure the slices were rinsed in several changes of PB. For immunohistochemistry the sections were stained free floating using the peroxidase-antiperoxidase-(PAP) procedure (12) with a polyclonal rabbit-antisomatostatin antiserum (Dr. Dubois, Nouzilly), and a rat monoclonal antibody against choline acetyltransferase (Boehringer Mannheim, FRG). Part of the sections were incubated with anti-SOM $(1: 1000)$ for $48 \mathrm{hr}$ at $4^{\circ} \mathrm{C}$. All other sections were stained with anti-ChAT using the avidin-biotin-peroxidase (ABC) method (6). Briefly, incubation times and dilutions were as follows: 1) preincubation with normal rabbit serum $(1: 50)$ in $\mathrm{PB}$ (containing $0.1 \%$ bovine serum albumin and $0.2 \%$ Triton $\mathrm{X}-100)$ for $2 \mathrm{hr}$ at room temperature; 2) anti-ChAT (1:6) in PB for $48 \mathrm{hr}$ at $4^{\circ} \mathrm{C} ; 3$ ) biotinylated anti-rat immunoglobulin G (Vector Lab., USA, $1: 100$ ) for $2 \mathrm{hr}$ at room temperature; 4) horse-radish-peroxidase (HRP)-avidin-d-complex (Vector Lab., USA, $1: 100$ ) for $2 \mathrm{hr}$ at room temperature. After each incubation step the sections were rinsed for $1 \mathrm{hr}$ in several changes of PB. Specificity controls were carried out using normal rabbit serum or by omitting the primary antibodies. The tissue slices were washed, mounted on glass slides using alcoholic gelatine and embedded in neutral balsam.

\section{RESULTS}

\section{ChAT/NADPH-d staining (Figs. 1, 2)}

As expected $(15,17)$, in the ST 2 populations of neurons are distinguishable by different staining according to this procedure. One population consisting of large, brown coloured cells was single ChAT immunostained. The second population showed only the NADPH-d reactivity (Fig. 1). NADPH-d positive cells appear much more numerous in this region than the cholinergic ones. Inside the globus pallidus only some ChAT immunolabelled neurons are found in its basal portion. NADPH-d stained cells are absent.

A number of ChAT/NADPH-d stained cells, recognizable by their intermediate brown-olive colour are present besides single ChAT immunoreactive and single NADPH-d stained cells in the regions composing the BF. Double-stained neurons are very numerous in the MS-vDB and in the hDB (Fig. 2).

Double- and single-stained neurons are intermingled in the MS-vDB. Along the border to the intermediate lateral septal nucleus some small NADPH-d single-stained cells can be recognized. NADPH-d single-labelled neurons are very few (1\%) in the hDB. The distribution of ChAT/NADPH-d double-marked cells is restricted to the marginal zone of this nucleus. They are intermingled with single ChAT immunoreactive neurons in this region. A second population of only ChAT labelled cells forms the innermost, lateral part of this nucleus bordering the diagonal tract fibres.

Double stained cells are missing from the VP. Only single ChAT immunoreactive neurons and single NADPH-d marked neurons occur in the ChAT/NADPH-d stained sections. The last-mentioned are rare and their somata represent a small type of neuron. The NPM and SI-NB regions contain the 3 variants as described for the MS-vDB. But the majority of cells in the NPM show ChAT-immunoreactivity ex- 


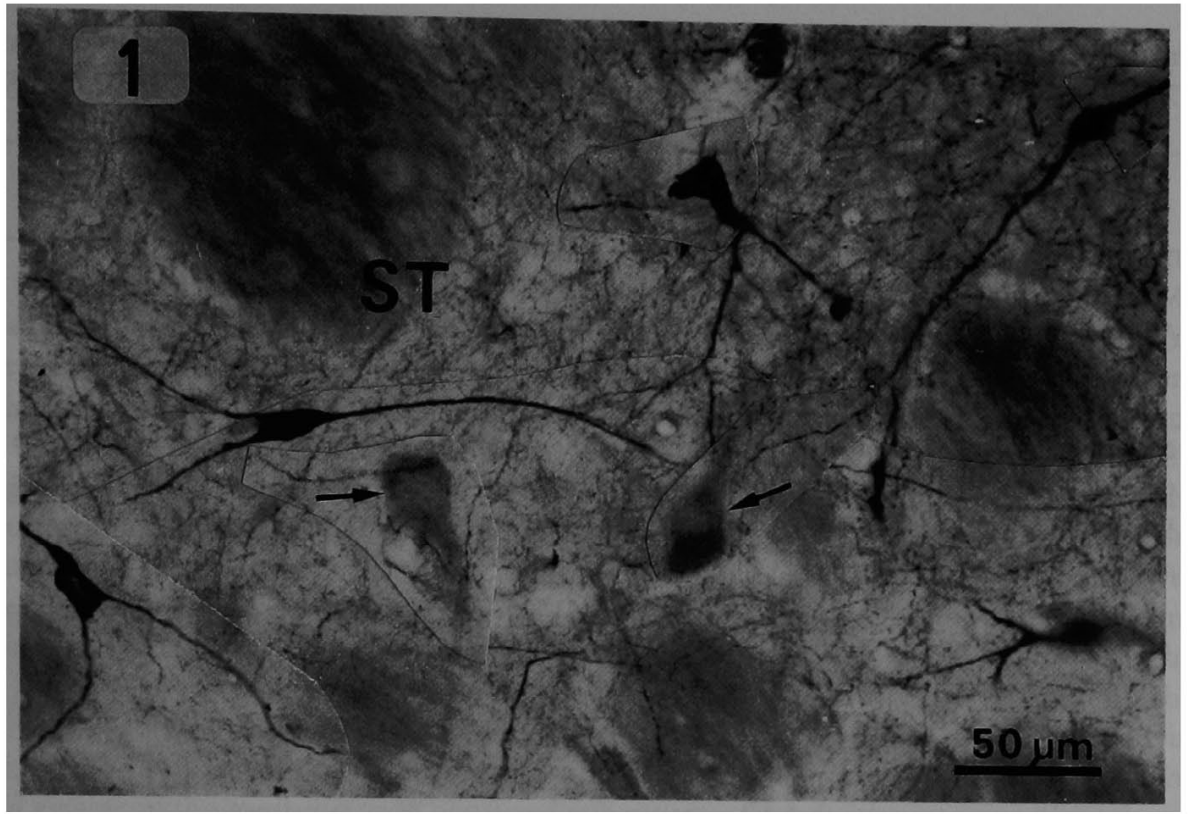

Fig. 1. ChAT and NADPH-d stained neurons in the ST. NADPH-d is known to be coexistent with SOM in this region. The arrows point to ChAT-positive cells.

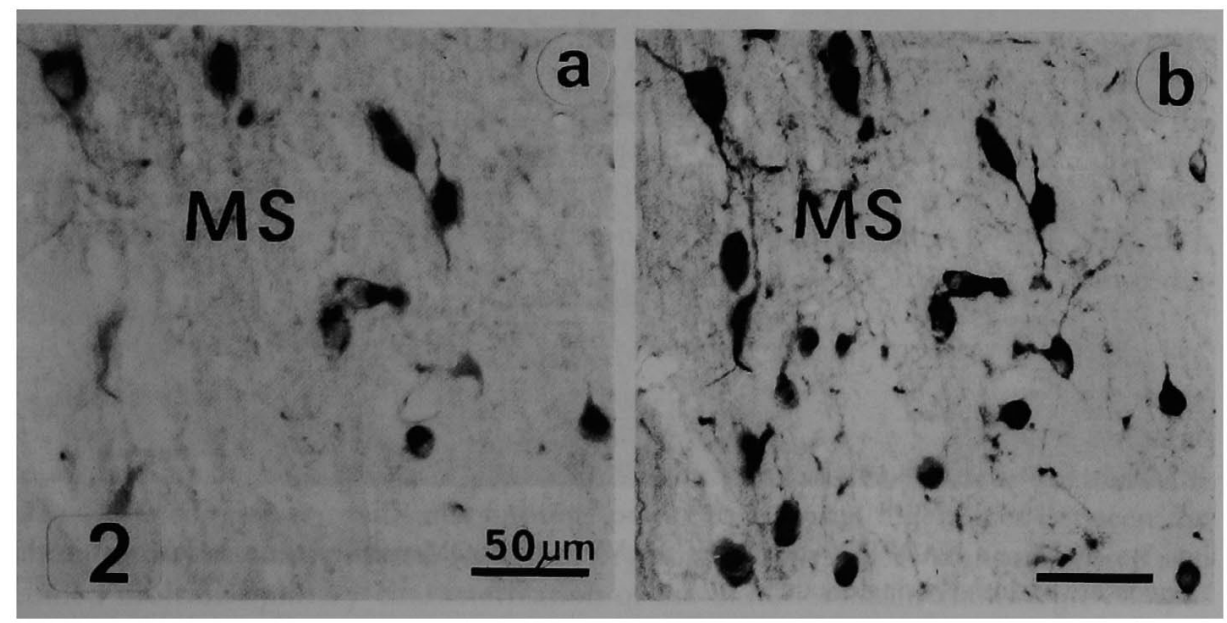

Figs. 2a, b. ChAT and ChAT/NADPH-d staining in the MS. a. Treated for NADPH-d histochemistry. b. The same region after additional application of ChAT-immunohistochemistry. The number of cells increased in b, as the single ChAT-labelled cells are added.

clusively (Table 1). Double-stained cells are distributed with single ChAT-immunostained cells in the more ventral portions of these nuclei. They are considerably numerous in their ventrolateral parts. Exclusively NADPH-d positive cells are rare in both regions. The cholinergic neurons around the globus pallidus, representing 
TABLE 1. Total number and proportion of labelled cells in the BF counted in 5 sections per region

\begin{tabular}{lccccc}
\hline \multicolumn{1}{c}{ BF-region } & MS-vDB & hDB & NPM & SI-NB & VP \\
\hline $\begin{array}{l}\text { labelled cells/ } \\
\text { section }\end{array}$ & 505 & 790 & 650 & 135 & 113 \\
\hline ChAT (n/\%) & $235 / 52$ & $505 / 64$ & $470 / 75$ & $35 / 26$ & $85 / 75$ \\
NADPH-d (n/\%) & $65 / 8$ & $10 / 1$ & $60 / 7$ & $45 / 33$ & $28 / 25$ \\
$\begin{array}{l}\text { double-stained } \\
(n / \%)\end{array}$ & $205 / 40$ & $275 / 35$ & $120 / 18$ & $55 / 41$ & $0 / 0$ \\
\hline
\end{tabular}

MS-vDB: medial septal nucleus-vertical limb of the diagonal band, $\mathrm{hDB}$ : horizontal limb of the diagonal band, NPM: nucleus preopticus magnocellularis, SI-NB: substantia innominatanucleus basalis Meynert-complex, VP: ventral pallidum.

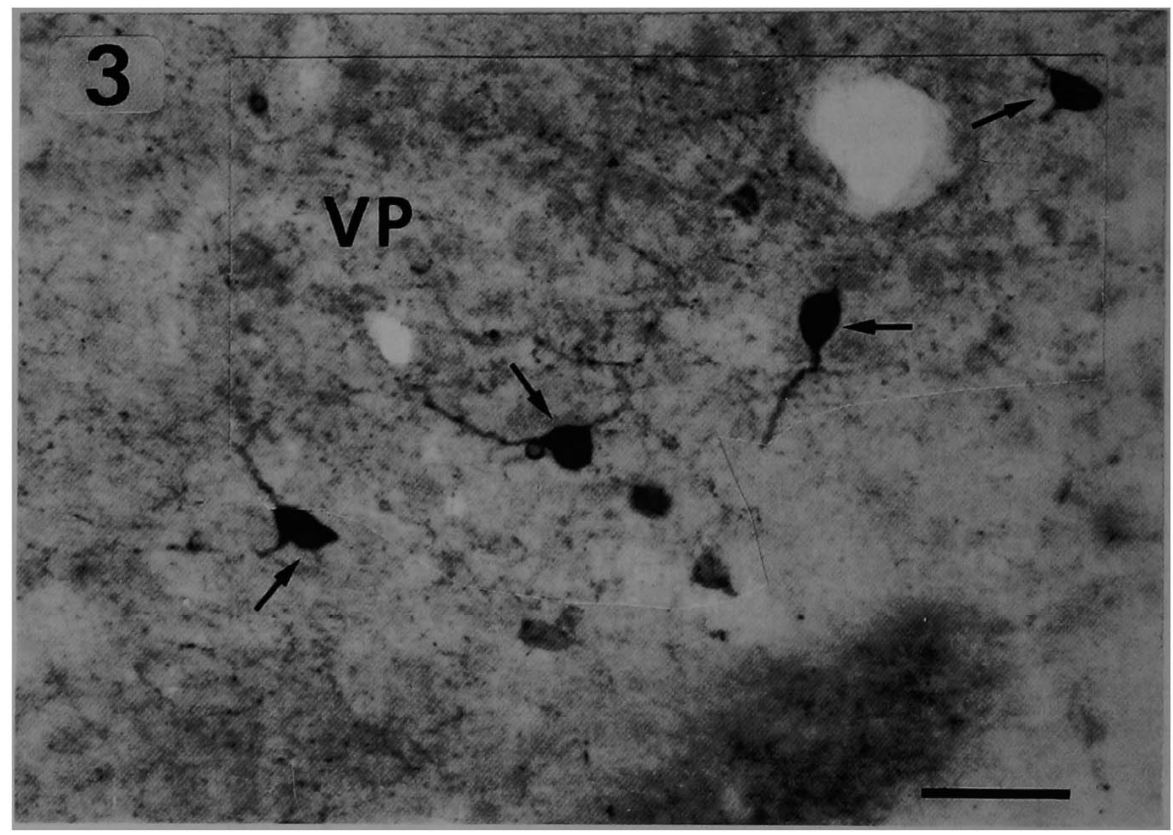

FIG. 3. SOM and NADPH-d staining in the VP. The SOM-positive neurons (arrows) in this region are exclusively single stained.

the most dorsal portion of the SI-NB, are found to be only single ChAT-immunostained. The proportions of the 3 differently coloured cell groups described in the BF regions are shown in Table 1.

$S O M / N A D P H-d$ staining (Fig. 3)

SOM containing neurons in the ST are double-stained with NADPH-d, recognizable by their gray instead of brown colour.

In the BF SOM-containing cells represent a small type. They can be found in a 
small number only in the VP, NPM and SI-NB. In these SOM-containing neurons NADPH-d is not colocalized, as can be recognized by their brown colour (Fig. 3).

\section{DISCUSSION}

In the ST the existence of 2 neuronal populations visualized separately according to the SOM or ChAT-immunohistochemistry was described $(15,17)$. In the SOMcontaining neurons neuropeptide Y (NPY) and C-PON (C-flanking peptide of NPY) were found to be coexistent (13). Contrary to the cholinergic neurons these cells were selectively marked by the use of NADPH-d histochemistry $(13,14)$. The coexistence of NADPH-d with SOM and NPY was also proved for neurons in other forebrain regions like olfactory bulb $(4,11)$. In our ST preparations the single ChAT-immunostained and the NADPH-d stained cells are clearly distinguishable in accordance with the findings of foregoing authors mentioned $(15,17)$ (Fig. 1). Contrary to the ST in the BF double-labelling with NADPH-d was not observed in the SOM-containing cells, but it was demonstrable in the cholinergic neuronal component. The SOM positive cells occur in a moderate number in the VP and are very scarce in the NPM and SI-NB. Colocalization of ChAT and NADPH-d was already found in other brain regions of the rat. Vincent et al. (16) described this type of coexistence for cell groups of the midbrain and pontine tegmentum. Besides this enzyme also several peptides, such as substance $P$, corticotropin-releasing factor and bombesin/gastrinreleasing peptide, were found to be present in the same cells.

The distribution of single ChAT-immunoreactive cells and those stained additionally according to the NADPH-d histochemistry is inhomogeneous in the BF. Several populations consist only of single ChAT labelled cells, in others single- and double-stained cells are intermingled. In two series of the rat forebrain treated for the immunoreaction of substance $\mathrm{P}$ and NADPH-d histochemistry (unpublished observations) only fibres, but no cells were found to be labelled in these regions. Ljungdahl et al. (7) described only very few substane $P$ containing cells in the rat $\mathrm{hDB}$. From this it follows that ChAT/NADPH-d double-labelled neurons in the BF do not contain this peptide, contrary to the tegmental cholinergic neurons.

NADPH-d positive cells also occur in the cats MS-vDB, hDB and SI-NB (9). In the human SI-NB NADPH-d and acetylcholinesterase (AChE)-positive cells were described to be intermingled, but no double-staining was noted (3). The same authors report on the absence of NADPH-d marked cells in the human VP and MSvDB. The comparison with our findings points to essential differences between the human and rat neuronal basal forebrain organization. A more comprehensive and detailed multidisciplinary characterization of the basal forebrain cholinergic component, especially with respect to the possible coexistence with other neuroactive substances (5), may elucidate the functional consequences of these findings.

\section{ACKNOWLEDGEMENTS}

The authors thank Miss M. Volkmann for the excellent technical assistance, Dr. M. Steingrueber, Leipzig, Dr. M. Frotscher, Frankfurt and Dr. M. P. Dubois (+), Nouzilly, for kindly providing the PC $128 \mathrm{D}$, the ChAT and SOM antibodies. 


\section{REFERENCES}

1. Bennett-Clarke, C., Romagnano, M.-A. and Joseph, Sh. A.: Distribution of somatostatin in the rat brain: telencephalon and diencephalon. Brain Res. 188; 473-486, 1980.

2. Bigl, V., Woolf, N. J. and Butcher, L. L.: Cholinergic projections from the basal forebrain to frontal, parietal, temporal, occipital, and cingulate cortices: a combined fluorescent tracer and acetylcholinesterase analysis. Brain Res. Bull. 8; 727-749, 1982.

3. Ellison, D. E., Kowall, N. W. and Martin, J. B.: Subset of neurons characterized by the presence of NADPH-diaphorase in human substantia innominata. J. comp. Neurol. 260; 233$245,1987$.

4. Gaspar, P., Berger, B., Lesur, A., Borsotti, J. P. and Febvret, A.: Somatostatin 28 and neuropeptide $\mathrm{Y}$ innervation in the septal area and related cortical and subcortical structures of the human brain. Distribution, relationship and evidence for differential coexistence. Neuroscience $22 ; 49-73,1987$.

5. Hoekfeld, T., Millhorn, D., Seroogy, K., Tsuro, Y., Ceccatelli, S., Lindh, B., Meister, B., Melander, T., Schalling, M., Bartfai, T. and Terenius, L.: Coexistence of peptides with classical neurotransmitters. Experientia 43; 768-780, 1987.

6. Hsu, S. M., Raine, L. and Fanger, H.: Use of avidin-biotin-peroxidase complex (ABC) in immunoperoxidase techniques: A comparison between $\mathrm{ABC}$ and unlabelled antibody (PAP) procedures. J. Histochem. Cytochem. 29; 577-580, 1981.

7. Ljungdahl, A., Hoekfelt, T. and Nilsson, G.: Distribution of substance P-like immunoreactivity in the central nervous system of the rat.-I. Cell bodies and nerve terminals. Neuroscience 3; 861-943, 1978.

8. Mesulam, M.-M., Mufson, E. J., Wainer, B. H. and Levey, A. I.: Central cholinergic pathways in the rat: an overview based on an alternative nomenclature ( $\mathrm{Ch} 1-\mathrm{Ch} 6)$. Neuroscience $10 ; 1185-1201,1983$.

9. Mizukawa, K., Vincent, S. R., McGeer, P. L. and McGeer, E. G.: Distribution of reducednicotinamide-adenine-dinucleotidephosphate diaphorase-positive cells and fibres in the cat central nervous system. J. comp. Neurol. 279; 281-311, 1989.

10. Scherer-Singler, U., Vincent, S. R., Kimura, H. and McGeer, E. G.: Demonstration of a unique population of neurons with NADPH-diaphorase histochemistry. J. Neurosci. Meth. 9; 229$234,1983$.

11. Scott, J. W., McDonald, J. K. and Pemberton, J. L.: Short axon cells of the rat olfactory bulb display NADPH-diaphorase activity, neuropeptide Y-like immunoreactivity. J. comp. Neurol. 260; 378-391, 1987.

12. Sternberger, L. A.: Immunohistochemistry. Wiley and Sons, New York, 1979.

13. Villalba, R.-M., Martinez-Murillo, R., Blasco, I., Alvarez, F. J. and Rodrigo, J.: C-PON containing neurons in the rat striatum are also positive for NADPH-diaphorase activity. A light microscopy study. Brain Res. 462; 359-362, 1988.

14. Vincent, S. R.: NADPH-diaphorase histochemistry and neurotransmitter coexistence. In Neurohistochemistry: Modern Methods and Applications, ed. by P. Panula et al., Liss, New York, 1986, p. 375-396.

15. Vincent, S. R., Johansson, O., Hoekfelt, T., Skirboll, L., Elde, R. P., Terenius, L., Kimmel, J. and Goldstein, M.: NADPH-diaphorase: a selective histochemical marker for striatal neurons containing both somatostatin-and avian pancreatic polypeptide (APP)-like immunoreactivities. J. comp. Neurol. 217; 252-263, 1983.

16. Vincent, S. R., Satoh, K. and Armstrong, D. M., Panula, P., Vale, W. and Fibiger, H. C.: Neuropeptides and NADPH-diaphorase activity in the ascending cholinergic reticular system of the rat. Neuroscience 17; 167-182, 1986.

17. Vincent, S. R., Staines, W. A. and Fibiger, H. C.: Histochemical demonstration of separate populations of somatostatin and cholinergic neurons in the rat striatum. Neurosci. Lett. 35; 111-114, 1983. 